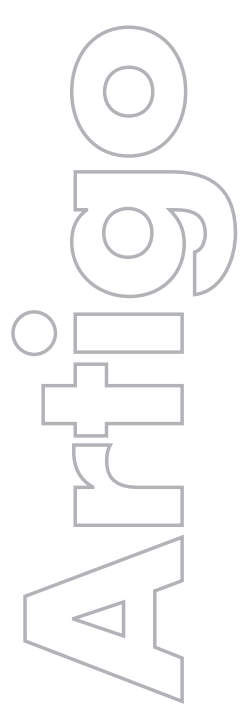

revista

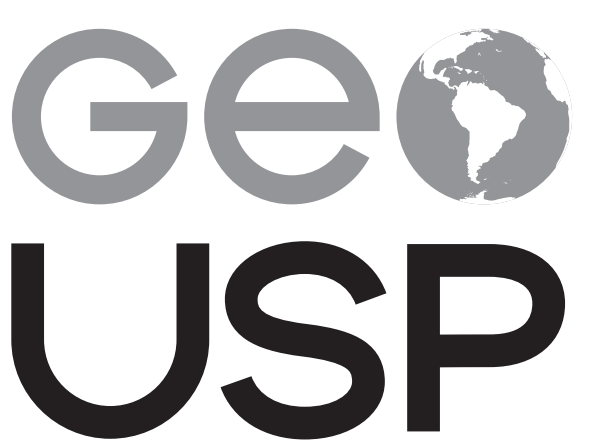

espaço e tempo

Volume $23 \cdot n^{\circ} 1$ (2019)

ISSN 2179-0892

\section{Espetáculo, alienação} espacial e queda tendencial do valor de uso na obra de Guy Debord

Glauco Roberto Gonçalves

UFG

e-mail: glauco.goncalves@usp.br

p. $059-075$

Como citar este artigo:

GONÇALVES, G. R. Espetáculo, alienação espacial e queda tendencial do valor de uso na obra de Guy Debord. Geousp Espaço e Tempo (Online), v. 23, n. 1, p. 059-075, abr. 2019. ISSN 2179-0892.

Disponível em: https://www.revistas.usp.br/geousp/article/ view/150346. doi: https://doi.org/10.11606/issn.2179-0892. geousp.2019.150346.

\section{(C) $(1) \Theta$}

Este artigo está licenciado sob a Creative Commons Attribution 4.0 License. 


\title{
Espetáculo, alienação espacial e queda tendencial do valor de uso nos escritos de Guy Debord
}

\section{Resumo}

A noção de espetáculo na obra de Guy Debord é, ao mesmo, largamente usada e pouco conhecida. Não raro, o espetáculo se espetaculariza. Também é comum tomar-se o espetáculo como mero equivalente dos meios de comunicação em massa. Este texto procura abordar alguns pressupostos constitutivos da noção de espetáculo, bem como sua relação necessária com Marx. Hegel e Luckács (entre outros, nem sempre menos importantes). Diferentemente do espetáculo, os conceitos de alienação espacial e de queda tendencial do valor de uso, presentes e imanentes à obra debordiana, não são tão disseminados e utilizados. Tais conceitos são abordados neste texto buscando ampliar sua compreensão, bem como suas fortes possibilidades de relação e uso em pesquisas e estudos em Geografia Humana.

Palavras-chave: Espetáculo. queda tendencial do valor de uso. alienação espacial. Geografia Urbana. Guy Debord. Internacional Situacionista.

\section{Spectacle, spatial alienation and tendential fall in use value in the writings of Guy Debord}

\begin{abstract}
The notion of spectacle in Guy Debord's work is both widely used and little known at the same time. Not infrequently the spectacle is spectacular. Not less often is the show used as a mere synonym of the mass media. This text tries to address some assumptions that constitute the notion of spectacle, as well as its necessary relation with Marx, Hegel and Luckács (among others not always less important). Unlike the spectacle, the concepts of spatial alienation and tendential fall in use value, present and inherent in the Debordian work, are not so widespread and used. These concepts are approached in this text seeking to broaden their understanding as well as their strong possibilities of relation and use in the researches and studies in Human Geography.
\end{abstract}

Keywords: Spectacle. Tendential fall in value in use. Spatial alienation. Urban Geography. Guy Debord. International Situationist. 


\section{Introdução}

$\bigcirc$ texto que é aqui apresentado busca abordar elementos constitutivos cruciais da noção de espetáculo em Guy Debord. Para tato, recorre a alguns dos autores que influenciaram e contribuíram profundamente para as elaborações da obra debordiana. Tenta-se compreender a estrutura conceitual de espetáculo, que não raro é compreendido e usado de forma deturpada e/ou limitada. Parte dessa limitação pode ser atribuída à dificuldade de compreender o livro mais conhecido e importante de Guy Debord, A sociedade do espetáculo, onde, em estilo complexo e com escrita arrojada, ele recorre a aforismas e desvios.' Como se procura mostrar neste artigo, esse estilo intrincado implica uma estratégia política.

Todavia, mais do que explicar o espetáculo -tarefa tão improvável quanto equivocada- busca-se colocá-lo em movimento, em diálogo com autores e ideias presentes na obra de Debord. Evidentemente, este texto não consegue, nem se propõe, abordar o conceito de espetáculo em todas as instâncias possíveis; esse trabalho - provavelmente malfadado desde o princípio - exigiria um esforço colossal. Fica patente nas entrelinhas do texto a condição (bem como a limitação) do autor que escreve e que estuda o conceito de espetáculo na ótica da Geografia Urbana e do cotidiano.

Para além do conceito de espetáculo como se o anuncia no título, este texto procura abordar, compreender e dialogar com as ideias de alienação espacial e de queda tendencial do valor de uso (clássico desvio do conceito de queda tendencial da taxa de lucro de Marx) em Guy Debord, tomando-as, mais uma vez, na ótica de estudos e pesquisas presentes e possíveis no campo da Geografia Urbana.

\section{Espetáculo, alienação espacial e queda tendencial do valor de uso em Guy Debord}

Certamente, História e consciência de classes, de Lukács (2003), foi uma das maiores influências na obra de Debord (1997), por isso me parece relevante resgatar a afirmação sobre a confusão logo no início de seu livro, evidenciando e reforçando os inúmeros desdobramentos que o primeiro autor gerou no segundo. Esse fato, que pode parecer irrelevante, permite-nos compreender que Debord (1997) elaborou uma teoria e procurou desenvolvê-la, inclusive em sua forma de escrever, estabelecendo nexos entre os conteúdos de seus escritos e o modo de apresentá-los. Como mostrou Jappe (1998, p. 202), a mentira é uma presença constante no livro $A$ sociedade do espetáculo. Também a noção de falsificação - ao lado da de falsidade, bem como a palavra falsamente - pode ali ser largamente encontrada, pois tornou-se um pilar estrutural da reprodução crítica da sociedade e de sua economia. A mentira apresenta-se como clara, mas sua clareza é só aparente, portanto falsa. A única transparência da mentira é sua necessária aceitação social, sobretudo no plano do cotidiano, reproduzindo o fetiche para reproduzir o mundo da mercadoria. A limpidez explicativa alicerça a alienação.

\footnotetext{
1 "O uso desviado é o contrário à citação, da autoridade teórica sempre falsificada pelo simples fato de se ter tornado citação; fragmento arrancado do seu contexto, do seu movimento, da sua época como referência global e da opção extra que representa dentro dessa referência, exatamente reconhecida ou falseada. $\bigcirc$ desvio é a linguagem fluida da antiideologia. Ele aparece na comunicação que sabe que não pode deter nenhuma garantia em si mesma e definitivamente. Ele é, no mais alto nível, a linguagem que nenhuma referência antiga e supra-crítica pode confirmar. Ao contrário, sua própria coerência, em si mesmo e com os fatos praticáveis, pode confirmar o antigo núcleo de verdade que ele traz de volta. $\bigcirc$ desvio não fundamentou causa sobre algo exterior a sua própria verdade como crítica presente" (Debord, 1997, p. 134).
} 
A forma acabada das relações econômicas, tal como elas se mostram em sua superfície, em sua existência real e, por conseguinte, também nas representações pelas quais os portadores e os agentes dessas relações procuram fazer dela uma idéia clara, é bastante diferente e, de fato, contrária ao seu núcleo interior e essencial, mas oculto, e ao conceito que a ele corresponde. [...] seria supérfluo se a manifestação e a essência das coisas coincidissem imediatamente (Lukács, 2003, p. 75).

Todas as mercadorias são - de pronto - inteligíveis. Avançar no entendimento e na caracterização do espetáculo requer colocá-lo nessa relação e nesse desencontro produzidos entre aparência e essência. Se, no espetáculo, a mentira é clara, em Guy Debord (1997) a confusão contém, por vezes, a explicação, mantendo a contradição. A clareza da mentira que move o espetáculo fez o autor buscar, também na confusão, um caminho explicativo. Por isso é possível identificar, inclusive na estrutura, na forma de seus textos, a dialética exercitando a contradição. Isso porque a forma é também um momento do conteúdo. O caráter meramente explicativo do pensamento burguês tinha de ser superado de modo radical. ${ }^{2}$

A sofisticada noção de espetáculo desenvolvida por Debord (1997) não seria possível sem a potente influência do conceito de fetiche exposto na obra História e consciência de classe, de Lukács (2003). Desse modo, faz sentido pensar o espetáculo como uma forma de atualização do fetiche da mercadoria, pois ele se coloca ao mesmo tempo como a forma de aparecer e convencer da mercadoria, e o meio de submeter o comportamento dos sujeitos. É de suma importância não perder de vista que a imagem não pode ser dissociada da forma de aparecer da mercadoria, pois se a reprodução da mercadoria depende da imagem (de sua aparência e de seu aparecimento), não é menos verdade que a reprodução da imagem não pode existir dissociada da forma mercadoria.

A constatação da ação degradadora da troca de mercadorias voltada para o interior aponta claramente para a mudança qualitativa que nasce da dominação da mercadoria. Contudo, essa ação exercida no interior da estrutura social também não basta para fazer da forma mercantil a forma constitutiva de uma sociedade. Para tanto, ela tem de penetrar - como foi enfatizado acima - no conjunto das manifestações à sua própria imagem, e não simplesmente ligar-se exteriormente a processos voltados para a produção de valores de uso e em si mesmos independentes dela. Mas a diferença qualitativa entre a mercadoria como uma forma (entre muitas outras) do metabolismo social dos homens e a mercadoria como forma universal de conformação da sociedade não se mostra somente no fato de a relação mercantil como fenômeno isolado exercer no máximo uma influência negativa sobre a estrutura e a articulação da sociedade, mas no fato de essa diferença reagir sobre o tipo e a validade da própria categoria (Lukács, 2003, p. 196).

2 Desviado de Lukács (2003, p. 17): "O caráter meramente contemplativo do pensamento burguês tinha de ser superado de modo radical". 
Na essência da mercadoria reside o engodo em que a relação entre as pessoas aparece como relação entre coisas (Lukács, 2003, p. 194). Nota-se que a essência da mercadoria passa necessariamente pela aparência. Aparecer falsamente, como algo que não é, é o cerne da forma mercadoria e, por consequência, a concretização do fetiche. A ilusão é essencial na mercadoria e em seu modo de aparecer. A aparência da mercadoria esconde sua essência. Todas as mercadorias e cada uma delas, a seu modo, como parte do todo, devem organizar sistematicamente a operação que fará com que sua forma de aparecer seja qualquer coisa, menos o que realmente é. Eis aí a tal objetividade fantasmagórica de que falavam Marx (2004) e Lukács (2003, p. 194).

A presença e importância de Hegel (1992) em Lukács (2003) repete-se também em Guy Debord (1997). Este recorre ao primeiro para encarar dialeticamente a relação entre aparência e essência. É parte imanente do espetáculo a contraditória relação entre essência e aparência.

A forma é tão essencial à essência quanto esta é essencial a si mesma, não se pode apreender e exprimir a essência como essência apenas, isto é, como substância imediata ou pura auto-intuição do divino. Deve exprimir-se igualmente como forma e em toda a riqueza da forma desenvolvida, pois só assim a essência é captada e expressa como algo efetivo (Hegel, 1992, p. 30).

Em Marx (2004, p. 160) - que, como se sabe, também se valeu dos escritos de Hegel (1992), as representações já se realizam como efetividades, e como tal, tornam-se representações, constituindo o mundo invertido. Marx (2004) mostrou que a objetividade da produção material capitalista não estava em sua materialidade, mas em sua forma como totalidade totalizante.

Ao escrever que o olho tornou-se humano, Marx (2004), em poucas linhas, lembra que a coisa (mercadoria) também se tornou um comportamento humano, o que nos permite compreender que, quando diz que o olho tornou-se humano, diz de uma certa humanidade envolta em contradições e objetivações socioeconômicas. Assim, o olho humano de Marx (2004) não deve ser compreendido como um enaltecimento das qualidades e dos sentidos humanos, pois, se a totalidade da vida está envolta em relações capitalistas de produção, o olho - desde o surgimento da grande indústria - também se vê submetido a tais condições. Se o olho tornou-se humano na relação e na produção do mundo pelo homem, dialeticamente, ele se desumanizou quando foi capturado, produzido, pela magnitude com a qual o objeto social (mercadoria) foi colocado na condição de sujeito. $\bigcirc$ olho se humaniza na medida em que o humano se desumaniza, na medida em que a mercadoria se "humaniza". $\bigcirc$ olho torna-se sujeito na medida em que sujeita todos os outros sentidos humanos. ${ }^{3}$

3 Ainda nos Manuscritos econômicos e filosóficos, Marx (2004) ateve-se à análise dos sentidos e sentimentos humanos, pois compreendia não só sua dimensão e importância, como se vê adiante, mas também que essas características do humano estavam postas, relacionando-se contraditoriamente com as formas de reprodução social em curso. Na mesma medida em que se humaniza, assim como todos os demais sentimentos e sensações humanas, o olho se coisifica. Por certo, Debord (1997) parte daí. Para Marx (2004, p. 110), é "[...] apenas pela riqueza social objetivamente desdobrada da essência humana que a riqueza da sensibilidade humana subjetiva, que um ouvido musical, um olho para a beleza da forma, em suma as fruições humanas todas se tornam sentidos capazes, sentidos que se confirmam como forças essenciais humanas, em parte recém-cultivados, em parte recém-engendrados. Pois não só os cinco sentidos, mas também os assim chamados sentidos espirituais, os sentidos práticos (vontade, amor, etc.), numa palavra, o sentido 
olho se tornou olho humano, tanto subjetiva, como objetivamente. $\bigcirc$ olho se tornou um objeto social, humano, proveniente do homem para o homem. Por isso, imediatamente em sua práxis, os sentidos se tornaram teoréticos. Relacionam-se com a coisa por querer a coisa, mas a coisa mesma é um comportamento humano objetivo consigo própria e com o homem, e vice-versa. Eu só posso, em termos práticos, relacionar-me humanamente com a coisa se a coisa se relaciona humanamente com o homem. [...] Da mesma maneira, os sentidos e o espírito do outro homem se tornaram a minha própria apropriação. Além desses órgãos imediatos formaram-se, por isso, órgãos sociais, na forma da sociedade, logo, por exemplo, a atividade em imediata sociedade com outros etc., tornou-se um órgão da minha externação de vida e de um modo de apropriação da vida humana (Marx, 2004, p. 109).

A noção de representação hegeliana como aquilo que está lá onde a coisa não está, sendo ela inevitavelmente um signo, e não a presença da coisa em si (Safatle, 2007, p. 10) foi tomada como ponto de partida de Guy Debord (1997) em suas apreciações sobre o espetáculo. ${ }^{4}$ A noção de representação é, por isso, crucial no entendimento da cidade cenarizada, bem como no aprofundamento do entendimento do espetáculo em sua atual fase reprodutória. A representação coloca a presença da referência como aquilo que não pode ser realizado, como aquilo que não se dá nos limites da razão.

É preciso compreender o papel da representação no mundo espetacular e na reprodução do urbano. No espetáculo, a representação, como aquilo que não é, toma o lugar do que é. Torna-se então mais real que a coisa em si, transmutando a realidade num momento do que é falso.

No espetáculo, como na Fenomenologia do espírito, de Hegel (1992), a aparência se funde (confunde) com a essência. Mas, diferentemente do que se dá na Fenomenologia do espírito, no espetáculo, essa fusão (e confusão) não produz a consciência de si nem ruma no caminho do saber absoluto, mas engendra a inconsciência coletiva como fundamento da manutenção do mundo da mercadoria. Ao tomar o lugar da essência no espetáculo, a aparência torna-se essencial. A essência do mundo espetacular é sua própria aparência. Dito por Debord (1997, p. 16): "o espetáculo é a afirmação da aparência e a afirmação de toda vida humana isto é, social - como simples aparência".

A influência da obra e da dialética hegeliana em Guy Debord (1997) e nos fundamentos de $A$ sociedade do espetáculo é irrefutável. Não é por acaso que o primeiro aforisma desse livro afirma: "Tudo o que era vivido diretamente tornou-se uma representação" (Debord, 1997, p. 13).

humano, a humanidade dos sentidos, vem a ser primeiramente pela existência do seu objeto, pela natureza humanizada. A formação dos cinco sentidos é um trabalho de toda a história do mundo até aqui."

4 "Quando o mundo real se transforma em simples imagens, as simples imagens tornam-se seres reais e motivações eficientes de um comportamento hipnótico. $\bigcirc$ espetáculo, como tendência a fazer ver (por diferentes mediações especializadas) o mundo que já não se pode tocar diretamente, serve-se da visão como o sentido privilegiado da pessoa humana - o que em outras épocas fora o tato; o sentido mais abstrato e mais sujeito à mistificação corresponde à abstração generalizada da sociedade atual. Mas o espetáculo não pode ser identificado pelo simples olhar, mesmo que este esteja acoplado à escuta. Ele escapa à atividade do homem, à reconsideração e à correção de sua obra. É o contrário do diálogo. Sempre que haja representação independente, o espetáculo se reconstitui" (Debord, 1997, p. 18). 
Para Hegel, o signo está ligado à lógica da representação, de onde se segue a definição: "O signo é uma intuição imediata mas que representa um conteúdo absolutamente distinto daquele que a intuição tem para si; ele é a pirâmide para a qual uma alma estrangeira foi transferida e conservada" (Hegel, Enciclopédia, p. 458 apud Safatle, 2007).

Também em Marx (2004), Debord (1997) encontrou elementos estruturantes de seu pensamento. $\bigcirc$ fetiche da mercadoria em Marx (2004) evidenciava a transformação das relações humanas em relações entre coisas. ${ }^{5} \bigcirc$ espetáculo, como momento de aprofundamento do fetiche, transforma a relação entre coisas em relação entre imagens. A degradação da vida social passa do ser ao ter (Marx, 2004) e do ter ao parecer (Debord, 1997). Assim, Debord (1997) parte de Marx (2004) mobilizando seu pensamento, trazendo-o à tona não em movimento repetitivo e enfadonho - pura teorização -, mas de modo a potencializá-lo (ainda que, e sobretudo, por meio do desvio), procurando atualizá-lo dialeticamente, e por isso recorre sistematicamente à noção do fetiche na obra marxiana.

Para Jappe (1998, p. 35) o fetiche da mercadoria diz respeito ao contexto em que todos os momentos da vida foram reduzidos à natureza do valor. $\bigcirc$ espetáculo é a forma mais desenvolvida de alienação e do fetiche da mercadoria. Debord (1997) colocou em movimento o fetiche da mercadoria em sua inevitável e inegável relação com a totalidade e, por esse meio, tornou evidente que o legado sobre a totalidade posto por Lukács (2003), atrelado ao de Marx (2004) (que necessariamente partiu de Hegel [1992] e o inverteu), não poderia ser ignorado ou desprezado.

A mercadoria, também em sua fase espetacular, só pode ser compreendida se levada em conta como categoria universal de todo ser social, e é nesse contexto que a reificação adquire uma importância decisiva (Lukács, 2003, p. 198). "Foi o capitalismo a produzir pela primeira vez, com uma estrutura econômica unificada para toda a sociedade, uma estrutura de consciência - formalmente - unitária para o conjunto dessa sociedade" (Lukács, 2003, p. 221).

A universalidade da forma mercadoria condiciona, tanto objetiva quanto subjetivamente, o trabalho abstrato objetivado em mercadoria (Lukács, 2003, p. 200).

O conceito de espetáculo de Debord (1997) é - e só pode ser se for - aplicado à totalidade (Jappe, 1998, p. 210). Isso o distingue substancialmente daqueles que buscam compreender os problemas da mercadoria no cotidiano de forma fragmentária, recorrendo até hoje à ideia de

5 'A 'representação' é um processo essencial daquilo que Marx designou por fetichismo da forma da mercadoria. Não é só que o quantum de energia humana despendida não pode ser separado da forma concreta desse mesmo dispêndio; logo que os produtos se encontram produzidos, ele também pertence ao passado e já não é tangível, e por isso evidentemente não está 'contido' nos produtos em sentido natural ou físico. A 'representação' como processo físico nessa medida ocorre apenas nas cabeças dos sujeitos sociais assim constituídos, nomeadamente como percepção e 'tratamento' práticos fetichizados da sua própria sociabilidade. Ainda assim, tal 'representação' refere-se a algo que de facto não ocorre apenas nas cabeças dos sujeitos, como forma de percepção e de acção, mas que é uma realidade física, a saber, processos de combustão passados ocorridos em corpos humanos, dispêndio de unidades energéticas. Como o quantum de energia gasta no processo do seu dispêndio não pode ser realmente separado da forma ou determinação concreta desse mesmo dispêndio, e como, tratando-se de um dispêndio definitivamente passado, não pode literalmente estar 'contido' nos objectos, a forma social de representação é de facto neste aspecto irreal em duplo sentido. Mesmo assim, esse quantum de energia teve de ser despendido realmente no passado, pelo que, por outro lado, representa uma substância física real (se bem que 'representada' de modo paradoxal). A forma da representação dessa substância real, porém, nada tem em si de físico, sendo antes uma abstracção real, um modo de percepção e de acção socialmente constituído, em que as substâncias naturais e os bens produzidos são realmente tratados como se fossem objectos físicos de pura representação de processos de combustão passados em corpos humanos" (Kurz, 2005, p. 17). 
indústria cultural ou de mass media. $\bigcirc$ espetáculo não é uma produção qualquer, específica; é a produção que produz todas as outras. A crítica debordiana não se dirige à imagem como tal, mas à forma imagem como desenvolvedora da forma valor (Jappe, 1998, p. 197).

Anselm Jappe (1998) afirma que, atuando na totalidade, o espetáculo substitui a realidade por imagens, e nesse processo a imagem torna-se real, sendo causa de um comportamento real, como expôs Debord (1997). Daí em diante, para compreender a imagem, é preciso abolir a imagem que a imagem tinha. Agora não existe mais imagem sem fetiche, ela (imagem) torna-se o que há de mais "palpável" na mercadoria. É ela a voz, o olho, a cara do fetiche. Como parte integral das engrenagens do espetáculo, ela, a imagem, é o que se faz ver, o que se quer fazer ver; mas nunca é só o que foi visto. No espetáculo, a imagem realiza, mentindo, a simbiose entre o aparecimento e o conteúdo, o que mais uma vez permite falar da importante influência da dialética hegeliana entre essência e aparência na obra debordiana - ali usada, transformada e, afirmo, potencializada. Ela, a aparência, atua no lugar do conteúdo, fazendo ver o que quer produzir como ser. A imagem, como forma acabada reduzida e redutora da aparência, é a produção incessante do espetáculo e de seu discurso, ao passo que só pode ser produzida por ele. Seu vazio é - confusão como explicação - a completude que preenche falsamente o mundo. É nesse vazio que o valor de troca se "qualifica" para além da quantificação dos tempos do capitalismo industrial. A imagem da sociedade do espetáculo é a produção que produz todas as outras. . O conceito de imagem, em Debord (1997), deve ser avaliado como parte do desenvolvimento interior da mercadoria (Jappe, 1998, p. 38). A imagem posta pelo espetáculo é determinada pela socialização que opera a forma mercadoria. $O$ espetáculo possibilita que tudo agora seja quantificado também por meio de imagens. $\bigcirc$ valor de troca cria sua maneira mais sofisticada de se expressar por meio delas. Elas não são só a voz, mas também o modo de falar, e o espetáculo é o meio pelo qual o valor de troca se confirmou como a razão de ser do vivido. "Tudo o que era vivido diretamente tornou-se representação", o que tornou a vida das sociedades modernas "uma imensa acumulação de espetáculos" (Debord, 1997, p. 13). Isso porque "o mundo real se transforma em simples imagens [...] o mundo já não pode se tocar diretamente, serve-se da visão como sentido privilegiado da pessoa humana" (Debord, 1997, p. 18).

Em Debord (1997), a imagem não pode mais ser separada da totalidade social, nem pode ser vista como secundária nessa totalidade. Mas não estamos falando de qualquer imagem: ingênua ou vulgar. $\bigcirc$ espetáculo consiste no vivido posto como representação. Consiste na redução do real à imagem (Jappe, 1998, p. 22). Não foi o espetáculo que se submeteu à lógica da imagem: a imagem é que foi submetida à lógica espetacular.

No e pelo espetáculo, até mesmo as noções de temporalidade são alteradas. A reificação paralisa o tempo. $O$ tempo abstrato é, também, a abstração do tempo. A noção de duração é posta em xeque, posta pelo tempo abstrato, que se realiza realizando a mercadoria. $\bigcirc$ tempo da mercadoria é a duração de quê? $\bigcirc$ cotidiano posto de joelhos diante da mercadoria "entende", vivencia o tempo como possibilidade de duração da troca.

Em Debord (1997), o aprofundamento do "caráter contemplativo do capitalismo" foi entendido como oposto da vida, como não vivido. Assim, no plano do cotidiano, o espetáculo remete ao sequestro da vida, impondo-lhe uma paralisia asfixiante, tornando-a inerte, fazendo esvair-se sua capacidade de ação; desse modo, ascende com toda a força a condição do sujeito 
sujeitado não só à relação capital-trabalho, como bem apontou Kurz (2004), mas também à eterna condição de espectador, inclusive da própria vida e da própria não experiência vivida. Na cotidianidade, o espetáculo é uma máquina de moer e estraçalhar a potência do vivido, retirando dele tudo aquilo que pode ser vendido e mediado por imagem. A imagem é o resultado mais recente da realização do capital no cotidiano, fazendo aparecer tudo o que já não pode mais ser experiência. A imagem é a síntese do não vivido, é a linguagem translúcida da sobrevivência ampliada. Uma vida cotidiana libertada seria proporcionalmente inversa ao fetiche da mercadoria (Jappe, 1998, p. 40). O que na vida tornou-se opaco e obscuro, o espetáculo-com sua infinita e incessante fábrica de fazer ver - torna translúcido. Não é nada absurdo pensar na prostituição do imaginário (Baudrillard, 1995) de modo que a alucinação do real aparece em versão ideal e simplificada, mas nem por isso fácil de ser compreendida, muito menos superada.

$\bigcirc$ espetáculo atua como o grande responsável pela eliminação das distâncias e barreiras entre a economia política e sua realização plena no cotidiano. Ele não é uma categoria econômica, mas sim a vitória da economia no interior da sociedade. É o desenvolvimento ao extremo da abstração. É a religião laica do capital em sua reprodução crítica.

O cerne do espetáculo está em Lukács (2003, p. 222), o qual identifica os mecanismos de funcionamento do fetiche da mercadoria e, num determinado momento, fala em "espectador do devir social" e no sujeito que assume "uma atitude contemplativa em relação ao funcionamento de suas próprias faculdades objetivadas e coisificadas". Foi esse mesmo autor quem identificou pioneiramente o que chamou de "caráter contemplativo do capitalismo": os seres limitados à aparência do fenômeno, sem compreender a totalidade, a dimensão e os fundamentos do processo social em curso.

espetáculo atua para reunir ilusoriamente a sucessão de cisões que é própria das relações capitalistas de produção. $\bigcirc$ reencontro espetacular entre o trabalhador produtor e a mercadoria seu produto faz-se por meio do consumo. Entretanto, o desenvolvimento do fetiche e a sofisticação do espetáculo atuam no plano da totalidade para fazer desse aspecto elementar do capitalismo um mero detalhe. Advindo da brutal separação entre o trabalhador e aquilo que ele produz, o estranhamento apontado por Marx (2004) torna-se a matéria-prima de diferentes ramos do mercado, os quais passam a produzi-lo, movido pelo desejo de reencontro. $\bigcirc$ estranhamento é produzido como identificação na sociedade do espetáculo.

Momentos, experiências, temporalidades são tornados objetos na medida em que se tornam mercadorias; e, como objetos, são inevitavelmente colocados como estranhamento entre o sujeito e o objeto. Nessa operação, tempo e espaço transformam-se em produtos complexos, gerando estranhamentos não menos complexos. Aqui a separação entre sujeito e objeto destitui-se do sentido a ela conferido por outras mercadorias, pois todo transcorrer temporal do sujeito é posto no plano da mercadoria. $\bigcirc$ estranhamento vira condição sine qua non de toda existência humana, de modo que todo o transcorrer temporal, todas as formas de identificação e de realização espaço-temporais pressupõem o estranhamento como condição. $\bigcirc$ sujeito, em toda a sua existência temporal, é também o objeto mercadoria, pois a mercadoria cooptou todas as formas de uso do tempo. Tendo em vista que o sujeito é inevitavelmente uma existência espaço-temporal e que a mercadoria preencheu todo e qualquer tempo e espaço com os pressupostos do valor de troca, 
a existência, sua efetivação num dado lugar em determinado tempo é incondicionalmente a realização da mercadoria. ${ }^{6}$ E é nessa sinistra operação, que transforma estranhamentos em identificação, que o espetáculo opera, produzindo a aparência (como identificação) para suprir a essência (o estranhamento) e sua falta. $\bigcirc$ espetáculo como a contínua operação de convencimento de que a aparência (os sujeitos movem a mercadoria) é a verdadeira essência (a mercadoria se move movendo os sujeitos).

Assim, a alienação espacial é condicionada à temporalidade do vivido posta pelo estranhamento (e a condiciona), realizando-se ao realizar o objeto mercadoria. A negação da negação aqui é que o ser (consciência de si) só é, sendo também o outro (objeto mercadoria), então, só é possível ser (humano e sobreviver no planeta Terra por um punhado de anos) realizando o outro (objeto mercadoria). A realização do outro não é, então, neste caso, a negação de si mesmo?

estranhamento aparece tanto no fato de meu meio de vida ser um outro, no fato de aquilo que é meu desejo ser a posse inacessível de um outro, quanto no fato de que cada coisa mesma é um outro enquanto si mesma, quanto [também] pelo fato de que minha atividade é um outro, quanto finalmente - e isto vale também para os capitalistas - no fato de que, em geral, o poder não humano domina (Marx, 2004, p. 147).

A aparente autonomia dos objetos quanto às relações de trabalho é só aparente. No estranhamento - apontado por Marx (2004) nos Manuscritos como separação entre o produtor e o produzido - reside parte da impossibilidade de compreender o processo social e lidar com ele, o que dá asas à contemplação passiva. "La contemplation est évidemment liée à la séparation" (Jappe, 1998, p. 45). O espetáculo realiza em conjunto a totalidade do separado, do cindido, do fragmentado.

Já nos Manuscritos, Marx (2004, p. 91) afirmava que a condição de trabalhador impossibilita a existência do homem. Assim, a impossibilidade de viver, a vida sucumbida ao capital, já estava posta como condição em sua obra. E, se é irrefutável que o espetáculo de Debord (1997) funda-se nas obras de Marx (com algum destaque para os Manuscritos), também a crítica à redução do vívido recolheu daí uma contribuição relevante:

[... o capital é o homem totalmente perdido de si, assim como existe, no capital, objetivamente [o fato de] que o trabalhador é o homem totalmente perdido de si. Mas o trabalhador tem a infelicidade de ser o capital vivo e, portanto, carente, que, a cada momento em que não trabalha, perde seu juros e, com isso, sua existência. [...] $\bigcirc$ trabalhador produz o capital; o capital produz o trabalhador. E, aí, ele tem existência não enquanto homem, mas enquanto trabalhador, podendo deixar-se enterrar, morrer de fome etc. $\bigcirc$ trabalhador só é, enquanto trabalhador, assim que é para si como capital, e só é, como capital assim que um capital é para ele. A existência do capital é a sua existência, sua vida, tal como determina o conteúdo de sua vida de um modo indiferente a ele (Marx, 2004, p. 91).

6 "O espacial é a imersão do homem, como sociedade e indivíduo, no mundo da mercadoria" (Damiani, 2008, p. 29). 
Jappe (1998, p. 46) observa que a capacidade de o espetáculo recompor ilusoriamente a sociedade fragmentada está presente em Debord (1997) e esteve, a seu modo, em Lukács (2003), que como se sabe, partiu das contribuições de Hegel (1992) e Marx (2004), e procurou resgatá-las. No plano do urbano é possível identificar esse movimento; por isso, insistimos que a ideia de cidade só pode hoje tomar corpo em sua condição espetacular, como mentira verdadeiramente realizada; de modo que o processo de explosão-implosão abordado por Lefebvre (2000) só pode ser desfeito/refeito ilusoriamente. Não à toa, Anselm Jappe (1998, p. 47) fala em "reconstruction de la totalité, comme dictature totalitaire du fragment".

As considerações sobre a alienação espacial traçadas pelos situacionistas, fundamentalmente expostas por Debord (1997), têm, mais uma vez, uma importante influência de Lukács (2003), bem como de seu importante percurso nos escritos de Hegel (1992).

O tempo é a alienação necessária, como o demonstrava Hegel, o meio em que o sujeito se realiza ao se perder, tornando-se outro para tornar-se a verdade de si mesmo. Mas seu contrário é justamente a alienação dominante, que é sofrida pelo produtor de um presente estranho. Nessa alienação espacial, a sociedade que separa pela raiz o sujeito e a atividade que ela the subtrai, o separa primeiro de seu próprio tempo. A alienação social superável é justamente aquela que proibiu e petrificou as possibilidades e os riscos de alienação viva do tempo (Debord, 1997, p. 109).

Não há dúvida que de o esforço de Lukács (2003) para resgatar Hegel (1992) foi fundamental no avanço da teoria crítica marxiana. Esse esforço pode ser visto em todo o transcorrer de História e consciência de classe, inclusive no prefácio de 1967, quando já era evidente - ao menos para alguns - que era impossível descartar em conjunto a obra hegeliana. Ainda no prefácio de 1967, Lukács (2003, p. 26) lembra que, em Hegel (1992), a alienação "mostra-se idêntica à objetivação" e que "História e consciência de classes segue Hegel na medida em que nele a alienação também é equiparada à objetivação". Isso porque:

A objetivação é, de fato, um modo de exteriorização insuperável na vida social dos homens. Quando se considera que na práxis tudo é objetivação, principalmente $\mathrm{o}$ trabalho, que toda forma humana de expressão, inclusive a linguagem, objetiva os pensamentos e sentimentos humanos, então torna-se evidente que lidamos aqui com uma forma humana universal de intercâmbio dos homens entre si. Enquanto tal, a objetivação não é, por certo, nem boa nem má: o correto é uma objetivação tanto quanto o incorreto; a liberdade, tanto quanto a escravidão. Somente quando as formas objetivadas assumem tais funções na sociedade, que colocam a essência do homem em oposição ao seu ser, subjugam, deturpam, e desfiguram a essência humana pelo ser social, surge a relação objetivamente social da alienação e, como conseqüência necessária, todos os sinais subjetivos de alienação interna (Lukács, 2003, p. 27). 
A objetivação da essência da mercadoria no humano, tanto do ponto de vista teórico quanto prático, é necessária seja para fazer desumanos os sentidos do homem, seja para criar sentido humano correspondente à riqueza inteira do ser humano e natural. ${ }^{7}$

Convém lembrar que, em Marx (2004, p. 110), "todos os objetos tornam-se [a] objetivação de si mesmo para ele, objetos que realizam e confirmam sua individualidade enquanto objetos seus, isto é, ele mesmo torna-se objeto". Assim, o autor estabelece a inversão fundamental, da qual parte Debord (1997), de que a forma mercadoria é o verdadeiro sujeito do processo social, pondo os sujeitos (humanos) a ela sujeitados. Quando Marx (2004, p. 112) afirma que o "homem rico é simultaneamente o homem carente de uma totalidade da manifestação humana de vida", deixa claro que a forma mercadoria é também um processo que desumaniza. E essa é mais uma constatação marxiana da qual se valem tanto Debord (1997) como Vaneigem (2002).

Toda objetivação, tanto em Marx (2004) como em Lukács (2003), reitera o fetiche. No mundo invertido de Guy Debord (1997), toda objetivação é espetacular. A alienação espacial se concretiza (como abstração concreta) numa operação social de sofisticação da alienação e ampliação de seus horizontes. ${ }^{8}$ À cisão entre o produtor e o produto, própria das relações de trabalho da sociedade capitalista, somam-se outras; de modo que a alienação é também e necessariamente objetivação, e objetiva-se por todos os lados, na produção e no consumo.

A essência da estrutura da mercadoria já foi ressaltada várias vezes. Ela se baseia no fato de uma relação entre pessoas tomar o caráter de uma coisa e, dessa maneira, o de uma "objetividade fantasmagórica" que, em sua legalidade própria, rigorosa, aparentemente racional e inteiramente fechada, oculta todo traço de sua essência fundamental: a relação entre homens (Lukács, 2003, p. 194).

A objetivação é cada vez mais abstrata, mas não menos real. Conforme observa Lukács (2003, p. 46), Marx (2004) já apontava a objetivação como propriedade material primária de todas as coisas e relações, sendo agora necessário avançar no desvendamento de formas cada vez mais abstratas de objetivação, formas que prescindem da materialidade. Aqui o esforço caminha em busca da forma como as relações socioespaciais objetivam-se abstratamente, não necessariamente na materialidade, na concretude das formas espaciais, mas na forma abstrata de reprodução do mundo se concretizando, se objetivando. A lógica abstrata da mercadoria abstrai as condições e características do espaço (apropriado, vivido), tornando-o espaço abstrato. ${ }^{9}$ A alienação espacial aparece quando a objetivação se torna abstrata, pois todos os homens e suas realizações e relações se objetivam, sendo que na sociedade capitalista essa objetivação não se pode dar sem alienação. ${ }^{10}$ Quando as relações humanas - já devidamente tomadas pela objetivação como alie-

7 Desviado de Marx (2004, p. 111-112).

8 "O homem separado de seu produto produz, cada vez mais e com mais força, todos os detalhes de seu mundo. Assim, vê-se cada vez mais separado de seu mundo. Quanto mais sua vida se torna seu produto, tanto mais ele se separa da vida" (Debord, 1997, p. 25).

9 "O espaço abstrato é o espaço produzido pelo capitalismo. $\bigcirc$ espaço abstrato funciona 'objetivamente' como conjunto de coisas-signos, com suas relações formais [...]. Esse espaço formal e quantificado nega as diferenças" (Lefebvre, 2000, p. 60-61).

10 "O espetáculo na sociedade corresponde a uma fabricação concreta de alienação. A expansão econômica é sobretudo a expansão dessa produção industrial específica. O que cresce com a economia que se move por si mesma só pode ser a alienação que estava em seu núcleo original" (Debord, 1997, p. 24). 
nação - passam a se realizar num espaço exterior (no sentido da exteriorização posta por Marx nos Manuscritos, ou seja, cindido, não apropriável), a alienação espacial já não é mais ocasional. Assim, se já não é mais possível identificar nenhuma forma dos seres humanos e de suas relações objetivarem-se a não ser de modo alienado, também já não é mais possível pensar no espaço sem a alienação como condição. Se todas as relações objetivam a alienação, objetivamente a alienação é espacial, na medida em que todas as relações se espacializam.

É possível identificar nos Manuscritos de Marx (2004) algumas das primeiras decorrências da alienação espacial oriundas da separação entre o produtor e seu produto, que culminam na separação espacial entre o produtor e o produzido, fazendo com que aquele nem sequer se dê conta de aonde e para quem vai este. De forma que é possível afirmar que a alienação espacial surge e se desenvolve como parte imanente da alienação própria da modernidade, do desenvolvimento industrial. A complexidade assumida pelo moderno sistema produtor de mercadoria ao longo das últimas décadas amplia não apenas as noções de produção e de mercadoria, mas também a de alienação espacial. $\bigcirc$ produtor se vê destituído de muito mais do que aquilo que produz: vê todos os momentos de sua vida produzidos como mercadoria; sua inserção no espaço social é recoberta por uma infinidade de mercadorias sobrepostas sendo produzidas e reproduzidas, dificultando ainda mais o que se poderia chamar de "consciência espacial". A sofisticação adquirida pela reprodução social não é exclusivamente a de seus produtos (e das tecnologias neles aplicadas), mas também - e principalmente - é a sofisticação envolta na reprodução da sociedade como tal. A alienação espacial pode então ser posicionada como parte relevante, parte intrínseca, da reprodução social e das relações sociais de produção. Seu devido entendimento deve atingir o lugar ocupado pelo cotidiano no mundo da mercadoria, bem como o processo de urbanização da sociedade e da crise da cidade.

A alienação espacial realiza-se agora negando também a materialidade do espaço, o espaço concreto. Isso por meio do convencimento de uma nova concepção do espaço: um espaço imagético, não espacial, visual. A alienação espacial atingiu tal grau de complexidade que prescinde do espaço ("real") para se realizar. $\bigcirc$ espetáculo atua fazendo crer que espaço é tudo aquilo que se pode ver." "A especialização das imagens do mundo se realiza no mundo da imagem autonomizada" (Debord, 1997, p. 13).

As categorias econômicas tornam-se, portanto, dinâmicas e dialéticas em duplo sentido. Elas interagem constantemente como categorias "puramente" econômicas e nos ajudam a compreender todo corte temporal feito na evolução social. No entanto, como elas têm origem em relações humanas e funcionam nos processos de transformação das relações humanas, a marcha da evolução torna-se visível em sua relação recíproca com o substrato real de sua ação. Dito de outro modo, a produção e a reprodução de uma determinada totalidade econômica, que a ciência tem por tarefa conhecer, transforma-se necessariamente (na verdade, transcendendo a economia "pura", mas sem apelar a qualquer força transcendente que seja) em processo de produção e de reprodução de uma sociedade global determinada (Lukács, 2003, p. 88).

11 "O espetáculo na sociedade corresponde a uma fabricação concreta da alienação" (Debord, 1997, p. 24). 
A produção reprodução do espaço é também a (re)produção da sociedade e de suas relações sociais e econômicas. $\bigcirc$ fetiche da mercadoria toma forma quando, por um lado, ela se apresenta como objetividade; e, por outro, o comportamento do sujeito é submetido a ela (Lukács, 2003, p. 194).

Assim, a troca não pode ser entendida exclusivamente por sua condição quantitativa: ela é também qualidade "suprema" da sociedade capitalista. Ela penetra profundamente (qualitativa e quantitativamente) na sociedade, de modo que sua ação desagregadora destrói relações sociais e as recondiciona à sua própria imagem. Desse modo, a quantidade - por meio da lógica da mercadoria - também passa a aparecer como qualidade. $\bigcirc$ avanço da mercadoria sobre todos os momentos da vida reproduz a sociedade cada vez mais a sua verossimilhança. A forma mercantil é a forma universal da sociedade (Lukács, 2003, p. 196). Mais do que isso, a mercadoria é a categorial universal de todo o ser social (Lukács, 2003, p. 198).

As contradições envolvendo o valor de uso também foram apontadas por Lukács (2003, p. 203), que observou a não coincidência entre a unidade do produto como mercadoria e sua unidade como valor de uso: "Sendo assim é possível separar a produção de um valor de uso no espaço e no tempo [e] [...] essa fragmentação do objeto da produção implica necessariamente a fragmentação do seu sujeito".

$\bigcirc$ modo crítico como a sociedade da mercadoria se reproduz, na atualidade,convida-nos a pensar na reprodução da mercadoria destituída quase que totalmente de valor de uso. Para Anselm Jappe (1998, p. 27), a mercadoria já não tem nem uma fagulha de valor de uso.'2 Entretanto, a radical separação entre o valor de uso e o valor de troca não é uma novidade, podendo ser observada no célebre livro de Lukács (2003) História e consciência de classe, lançado na década de 1920.

Mais do que isso, tal separação pode ainda ser encontrada em diversas e significativas passagens de Marx (2011) em Grundrisse. Destaco aqui algumas:

A autonomização do valor de troca no dinheiro, destacado dos produtos, corresponde à autonomização da troca (do comércio) como função destacada dos trocadores [...] A finalidade do comércio não é diretamente o consumo, mas o ganhar dinheiro, valor de troca. Com essa duplicação da troca - a troca para o consumo e a troca pela troca - tem origem uma nova desproporção. [...] A dependência recíproca e multilateral dos indivíduos mutuamente indiferentes forma sua conexão social. Essa conexão social é expressa no valor de troca, e somente nele a atividade própria ou o produto de cada indivíduo devêm uma atividade ou produto para si; o indivíduo tem de produzir um produto universal - o valor de troca-, ou este último por si isolado, individualizado, dinheiro [...]. A atividade, qualquer que seja sua forma de manifestação individual, e o produto da atividade, qualquer que seja sua qualidade particular, é o valor de troca, um universal em que toda individualidade, peculiaridade é negada, apagada. [...]

12 De modo que, quando se fala em crise do valor, é preciso lembrar que a crise é também do valor de uso - fato comumente desprezado. Também a questão da queda tendencial do valor de uso, claro desvio de Debord (1997) do conceito de queda tendencial da taxa de lucro de Marx (2004), é posta em curso aqui por sua condição estruturante da obra de Debord (1997). Como também no caso da alienação espacial, tal conceito será abordado aqui e acolá, fragmentariamente (sobretudo por dificuldade deste que escreve), ao longo de diferentes passagens deste artigo. 
No valor de troca, a conexão social entre as pessoas é transformada em um comportamento social das coisas; o poder pessoal, em poder coisificado (Marx, 2011, p. 97/105).

A separação entre valor de troca e valor de uso aparece como separação daquilo que parecia inseparável. E, sobretudo a partir das décadas de 1950 e 1960, o avanço da reprodução do capital no bojo da cotidianidade e do urbano já se realiza sob a égide da forma mercadoria carregada de sua radical separação(entre troca e uso).

Os situacionistas falavam ainda em "valor consumível ilusório" (IS, 1999, p. 177), bem como em "sociedade do consumo vazio" (IS, 2007, p. 239), referindo-se ao aprofundamento desse processo de queda tendencial do valor de uso, que culmina no preenchimento ilusório da mercadoria.

É aqui ainda, na separação entre valor de troca e valor de uso, que a dialética entre necessidades e desejos (a qual moveu parte da preocupação e dos estudos de Henri Lefebvre (1961) no segundo volume de Critique de la vie quotidienne) ganha substância, tornando-se elementar para a realização da sociedade espetacular. A luta do espetáculo é também a luta pela perpetuação de seu modo operacional e de seus resultados. Ele deve atuar amortizando o estranhamento entre o produtor e o produzido e, para tal, produz ampliadamente o desejo. Se a reprodução da mercadoria já não é movida por sua utilidade, o que a move então? E quando falamos do espaço como mercadoria, se ele é oferecido e vendido não mais por suas possibilidades de uso, o que vende o espaço, já que não é a possibilidade de ele ser usado?

Marx (2004, p. 28) afirmou que a infelicidade da sociedade é a finalidade da Economia Política. A Economia Política Espetacular encarrega-se de produzir a pseudofelicidade mediada pela troca. $\bigcirc$ acirramento das contradições entre capital e trabalho, bem como a elevação do dinheiro aos céus, põe a necessidade de aprimoramento da Economia Política. Ela deve agora se preocupar em mascarar, esconder a infelicidade, ao mesmo tempo em que produz, como farsa, a felicidade por meio da troca. Marx (2004, p. 30) deixa claro que a Economia Política do período industrial limitava-se ao trabalho: "ela não considera seu tempo livre de trabalho". Mais uma vez, a evolução das relações capitalistas ampliou os horizontes da Economia Política, levando-a a atuar nos demais momentos da vida. Ou seria melhor dizer que a lógica do trabalho avançou sobre todos os momentos da vida?

$\bigcirc$ desenvolvimento das forças produtivas, a automação e a crise do trabalho dele decorrentes provocaram uma profunda alteração na forma como a Economia Política concebe o trabalhador. Se antes, por meio do salário, ele era entendido como "uma besta reduzida às mais estritas necessidades corporais" (Marx, 2004, p. 3), agora segue sendo concebido como besta, mas uma à qual se impõem as mais estapafúrdias necessidades e desejos. A produção do desejo é uma chave para avançarmos no entendimento de como se realiza o fetiche da mercadoria.

Marx (2004, p. 32) perguntava-se até que ponto os homens trabalham com máquinas e até que ponto trabalham como máquinas. $\bigcirc$ espetáculo traz novas questões que se sobrepõem a essa. Será que a produção dos desejos não fez o homem desejar como máquina? Hoje, trata-se, isso sim, de avançar na compreensão da máquina de produzir desejos, pois sabe-se que os homens - movidos por setores específicos da produção - foram tornados máquinas de desejar. 
aprimoramento das relações capitalistas, o cotidiano elevado à condição central na realização da mercadoria, isso fez com que a Economia Política do Espetáculo se desenvolvesse, por meios de fazer a infelicidade aparecer como satisfação. A moderna sociedade produtora de mercadorias move-se sob o mantra de que a felicidade só pode ser atingida por meio do consumo. A infelicidade é produzida por esta sociedade, que vende aquilo que pode, prometendo a felicidade.

Diante disso e contraditoriamente, uma das principais decorrências da sociedade do espetáculo é a drástica redução do valor de uso. Debord (1997) classificou esse processo desviando uma celebre definição de Marx (2004) - como queda tendencial do valor de uso.

$\bigcirc$ valor de uso que estava implicitamente compreendido no valor de troca deve ser agora proclamado de forma explícita na realidade invertida do espetáculo, justamente porque a realidade efetiva desse valor de uso está corroída pela economia mercantil super-desenvolvida; uma pseudo-justificativa torna-se necessária para a falsa vida (Debord, 1997, p. 34).

A constituição da sociedade do espetáculo tem seus pilares no desenvolvimento do mundo da mercadoria que amplia exclusivamente a potência do valor de troca e, simultaneamente, a depreciação do valor de uso. A voracidade do capital deve-se sobretudo a sua inerente necessidade de reprodução ampliada. Assim, o mundo da mercadoria avança com a realização do valor de troca, fazendo do valor de uso um empecilho. A sociedade do espetáculo cumpre seu papel quando avança na elevação do valor de troca da mercadoria cada vez mais desconcertada do valor de uso, dilacerando-o.

A satisfação que a mercadoria abundante já não pode dar no uso começa a ser procurada no reconhecimento de seu valor como mercadoria: o uso da mercadoria bastando a si mesmo para o consumidor, é a efusão religiosa diante da liberdade soberana da mercadoria. [...] Como nos arroubos dos que entram em transe ou dos agraciados por milagres do velho fetichismo religioso, o fetichismo da mercadoria atinge momentos de excitação fervorosa. $\bigcirc$ único uso que ainda se expressa aqui é o uso fundamental da submissão (Debord, 1997, p. 44/45).

\section{Conclusão: espaço e (ou?) espetáculo}

Longe de querer dar aqui um caráter geográfico ao espetáculo ou, mais vulgarmente, achar a geografia no/do espetáculo, procurei avançar na compreensão da espacialização espetacular da mercadoria e na espetacularização do espaço mercantilizado, que se relacionam e são inerentes ao processo social em curso. A teoria desenvolvida por Debord sobre a sociedade do espetáculo traz elementos significativos para a compreensão da espacialidade, do capitalismo e do cotidiano no mundo contemporâneo. $\bigcirc$ espetáculo não pode ser visto como um suplemento decorativo do mundo real, mas sim como o "âmago do irrealismo da sociedade real" (Debord, 1997, p. 14).

$\bigcirc$ espaço (abstrato) destituído de espacialidade (concreta) se efetiva como fluxo de imagem transmitida aos quatro cantos. A mercantilização do espaço urbano dá um novo salto e ruma para o conjunto de relações socioespaciais mediadas por imagens. A imagem do espaço, sua paisagem, torna-se sua parte mais concreta, seu objetivo único. $\bigcirc$ espaço ascende aos céus! 
A noção de cidade reduzida a cenário, presente na obra de Debord e nos textos da Internacional Situacionista , é o avesso do direito à cidade de Henri Lefebvre, pois nega, elimina com toda a força o uso e o usador em todas as suas instâncias. Para ser vista, exposta (nos termos propostos por Virilio, 2005), a cidade já não pode ser apropriada. A espacialidade tomada pela forma mercadoria encontra seus desígnios desenhando e desdenhando seus novos contornos e limites, e, neles, o vivido é reduzido ao visto.

\section{Referências}

BAUDRILLARD, J. Para uma crítica da economia política. Rio de Janeiro: Elfos, 1995.

DAMIANI, A. L. Espaço e geografia: observações de método - elementos da obra de Henri Lefebvre e a geografia. Tese (Livre-docência em Geografia Humana) - Faculdade de Filosofia, Letras e Ciências Humanas, Universidade de São Paulo, São Paulo, 2008.

DAMIANI, A. L. A crise da cidade: os termos da urbanização. In: DAMIANI, A. L.; CARLOS, A. F. A.; SEABRA, O. C. L. (Org.). O espaço no fim de século. São Paulo: Contexto/USP, 1999. p. 118-131.

$\mathrm{DEBORD}, \mathrm{G}$. Relatório sobre a construção de situações e sobre as condições de organização e de ação da tendência Situacionista Internacional (Texto de fundação da Internacional Situacionista, Cosio d’Arroscia, 1957). In: JACQUES, P. B. (Org.). Apologia da deriva: escritos situacionistas sobre a cidade. Trad. Estela dos Santos Abreu. Rio de Janeiro: Casa da Palavra, 2003. p. 43-59.

DEBORD, G. A sociedade do espetáculo. Rio de Janeiro: Contraponto, 1997.

DEBORD, G. Potlach (1954-1957). Paris: Gallimard, 1996.

HEGEL, G. W. F Fenomenologia do Espírito. 2 Ed., Parte I. Petrópolis: Vozes, 1992.

IS. INTERNACIONAL SITUACIONISTA. Sessão Inglesa. La Rioja: Pepitas, 2007.

IS. INTERNAZIONALE SITUAZIONISTA. Sessão Italiana. La Rioja: Pepitas, 2007.

IS. INTERNACIONAL SITUACIONISTA. Textos íntegros en castellano de la revista Internationale Situacionniste (1958-1969). Madrid: Literatura Gris, 1999.

IS. INTERNATIONALE SITUATIONNISTE. Paris: Arthème Fayard, 1997.

JACQUES, P. B. Elogio aos errantes. Salvador: Ed. UFBA, 2012.

JACQUES, P. B. (Org.). Apologia da deriva: escritos situacionistas sobre a cidade. Trad. Estela dos Santos Abreu. Rio de Janeiro: Casa da Palavra, 2003.

JAPPE, A. L'avant-garde inacceptable: réflexions sur Guy Debord. Paris: Lignes, 2004. JAPPE, A. Guy Debord. Paris: Via Valeriano/Sulliver, 1998. 
KURZ, R. A substância do capital: o trabalho abstracto como metafísica real social e o limite interno absoluto da valorização (Primeira parte: A qualidade histórico-social negativa da abstracção "trabalho"). Exit - Crise e Crítica da Sociedade da Mercadoria. 2005. Disponível em: www.obeco.planetaclix.pt/rkurz203.htm. Acesso em: 8 abr. 2019.

KURZ, R. O colapso da modernização: da derrocada do socialismo de caserna à crise da economia mundial. 6a ed. São Paulo: Paz e Terra, 2004.

LEFEBVRE, H. A revolução urbana. Belo Horizonte: Ed. UFMG, 2004.

LEFEBVRE, H. La production de l'espace. 4a ed. Paris: Anthropos, 2000.

LEFEBVRE, H. O fim da história. Lisboa: Dom Quixote, 1971.

LEFEBVRE, H. O direito a cidade. São Paulo: Documentos, 1969.

LEFEBVRE, H. Critique de la vie quotidienne. Paris: LArche, 1961. v. II: Fondements d'une sociologie de la quotidienneté.

LUKÁCS, Georg. História e consciência de classe. São Paulo: Martins Fontes, 2003.

MARX, K. Grundrisse. Rio de Janeiro: UFRJ/Boitempo, 2011.

MARX, K. Manuscritos econômicos e filosóficos. São Paulo: Boitempo, 2004.

MARX, K. O capital. 2a ed. São Paulo: Nova Cultural, 1985. v. 1.

SAFATLE, V. A fenomenologia do espírito, de Hegel. São Paulo, 2007. Disponível em: https://www.academia.edu/5857053/Curso_Integral_-_A_Fenomenologia_do_ Esp\%C3\%ADrito_de_Hegel_2007_. Acesso em: 8 abr. 2019.

VANEIGEM, R. A arte de viver para as novas gerações. São Paulo: Conrad, 2002.

VANEIGEM, R. Banalités de base I. Internationale Situationniste, Paris: Arthème Fayard, n. 7, 1962.

VIRILIO, P. O espaço crítico. Rio de Janeiro: Editora 34, 2005. 